\title{
In Poetic Association: Acts of Architecture in the Realm of Landscape Ecology
}

\author{
Brook Muller \\ University of Oregon, Eugene, OR
}

\begin{abstract}
This paper describes metaphorical engagement of ecology as a strategy for designing human inhabitation catalyzed by and supportive of healthy urban ecosystems. A case is made for the importance and timliness of collaboration and conceptual association between architects and landscape ecologists. Next, the Australian architect Richard Leplastrier's notion of architecture as "furnishing with particular purpose this larger room we are in" - suggestive of both the architect's role and the context of an architectural undertaking - is examined as a prototype for approaching problems of design in an environmentally sensitive manner. A pilot studio attempt to engage ecological issues through metaphor is described, and building from this experiment and Lepastrier's statement, a palette of "human act/environment" case study metaphors is offered for use in design. Lastly I offer a methodology for testing these metaphors in advanced architectural design studios and evaluating their influence on students' design thinking and the environmental responsiveness of projects that result.
\end{abstract}

Keywords: Architectural Design, Landscape Ecology, Metaphor

\section{INTRODUCTION}

While much research is underway to develop environmentally friendly building materials, advance energy performance and more efficiently "harvest" on site resources, and while flowing landscape-like forms captivate our collective imagination, architects' knowledge of principles of ecology and the sitespecific ecological impacts of building interventions are limited. What might rigorous engagement with the language of ecology, and more specifically landscape ecology, mean for architects? Might we summon more encompassing portrayals of our activities, descriptions that better enable design professionals to realize projects that minimize damage and perhaps engage in beneficial relationships with surrounding ecosystems? Can a metaphorical appropriation of working concepts in landscape ecology such as "peninsular interdigitation," patch/matrix "breaks" and "edge/corridor effects" alter how we understand problems of architecture and encourage shifts in methodological tactics? ${ }^{1}$ With continued pressure to develop remnant lands within and at the margins of our cities, can we envision a scenario where both architectural enterprise and ecological integrity are achievable?

In "revealing the importance of spatial patterning on the dynamics of interacting ecosystems," landscape ecology offers great relevance for architects. ${ }^{2}$ Perhaps the most spatially oriented subdiscipline of ecology, landscape ecology embraces intervention, intentionality and design as a means of ensuring healthy, functional and diverse ecosystems. While landscape ecologists undertake projects in a multiplicity of ecosystems at many scales, involving public or private land holdings or both, the discipline finds itself increasingly contending with the Jeffersonian, democratic small scale lot. Joan Iverson Nassauer recognizes the critical importance of this trend,

"We must work at this democratic scale of ownership, the single lot or the single farm or ranch, to achieve ecological health beyond public lands and beyond the anomalies of privileged and enlightened land development. In the United States, where recent legal decisions have tended to narrowly interpret public interests in limiting private-property rights, and where strong cultural traditions favor the rights of landowners to do what they deem most suitable on their land, overall ecological health depends on the aggregation of innumerable individual landowner's decisions." ${ }^{3}$

(c) 2007 ARCC Spring Research Conference, Eugene, Oregon, April 16-18, 2007 
With landscape ecologists increasingly concerned about environmental quality at the lot scale, even beginning to contemplate the impact of the building "footprint," a growing number of architects seek to more sensitively apprehend larger landscape ecological processes that are influenced by the configuration of buildings, to address for example the morphological implications of architecture given the need to preserve wildlife corridors that may exist on a site, or repair a corridor previously fragmented. As regimes of thought between these disciplines converge, metaphors, "nomadic terms that link disparate discourses," may be looked at as creative intellectual tools for extending ecological mediums into built form and built form into the landscape in a transformational and integrated manner. ${ }^{4}$ In developing a framework for metaphorical appropriation of concepts of landscape ecology so as to positively influence architectural thinking, I will first reflect on the Australian designer Richard Leplastrier's suggestion of the primary task of the architect as that of "furnishing with particular purpose this larger room we are in," a notion that continues to haunt me as an example of the profound influence novel articulations can have on conceptualizations of architecture at the outset of design investigations, and the environmental receptivity that poetic insight can encourage. ${ }^{5}$

\subsection{METAPHORICS AND POETICS OF FURNISHING THIS LARGER ROOM}

"People who have not lost the wholeness of their place can see their households and their regional mountains or woods as within the same sphere."-Gary Snyder ${ }^{6}$

In the 2001 Glenn Murcutt Architecture "Master" Class in New South Wales, Australia, students were asked to design a gallery in a bowl-shaped meadow adjacent to Murcutt's Riversdale Educational Retreat Center (1999). During a site visit in the preliminary stages of design, architect Richard Leplastrier suggested the task of the architect was to "furnish with particular purpose this larger room we are in," a notion that fostered a novel understanding of the designer's role and heightened receptivity towards landscape. Conceiving the gallery not as an object in a field but rather an assemblage of "furnishing-like" settings in a bowl-shaped room liberated students to "pull the building apart," to consider minimal provisioning of shelter for many of the space as acceptable, and to propose projects of dramatic efficiency, richness and environmental response.

This account from my own experience is revealing of the manner in which use of metaphor involves attempts to explain complex phenomenon via something tangible and comprehensible. ${ }^{7}$ Leplastrier's notion of "furnishing this larger room" may be said to involve two critical metaphorical presuppositions: (1) we may gain insight into the highly complex realm of architecture by assigning characteristics to architectural elements we more typically attribute to furnishings (such as economy, lightness and unpretentiousness), and (2) we gain insight into the highly complex realm of the environment by suggesting it has room-like qualities. Through a stratagem of poetic association, we combine these two notions to produce a strikingly new (third) meaning. I say striking and suggest Leplastrier's statement encourages design thinking resonant with contemporary concern over the environment. In particular it (1) suggests architecture takes part in something larger that demands sensitive acknowledgement and (2) helps us sidestep the nature/culture dichotomy and acknowledge the energetic purposefulness inherent to humans and to suggest possibilities for applying such energy constructively as we interact with the world around us.

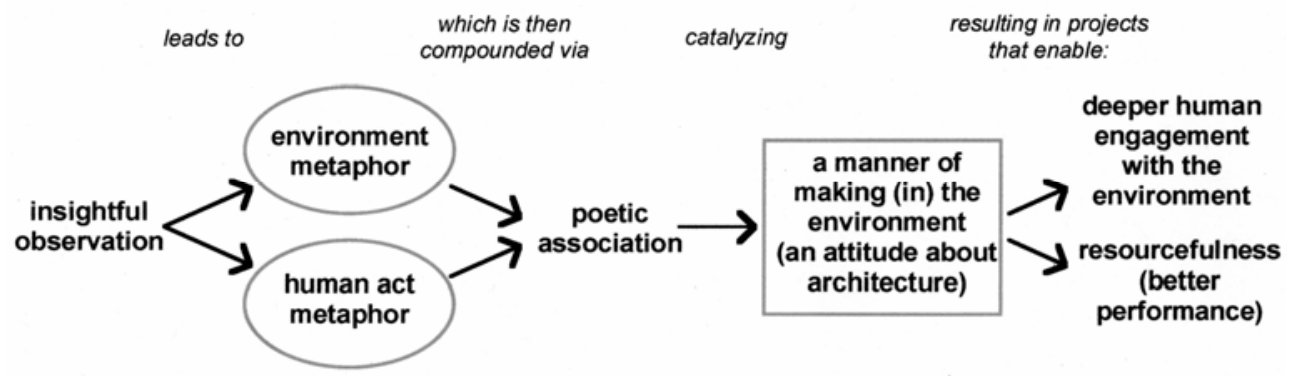

Figure 1: Two metaphors are compounded through poetic association to produce a new (third) meaning

(c) 2007 ARCC Spring Research Conference, Eugene, Oregon, April 16-18, 2007 
With the notion of architecture as furnishing this larger room, a built entity is less a boundary and more a mediator between our selves and larger entities, rooms at once tremendously spatially complex and comforting in their bounding comprehensibility. Our architectural furnishings, surfaces as bodily extensions and settings for gathering, are "outfoldings" towards our primary inhabitation, an environment, a horizon, a landscape under the stars. That such mindfulness of dwelling/inhabitation practices that find registration in the landscape might inspire works of architecture corresponds vividly with David Leatherbarrow's treatment of "The Topographical Horizon of Dwelling Equipment" in his groundbreaking work "Uncommon Ground." I quote three passages from the book:

"No single element in a spatial ensemble is positioned to stand out from all the rest; no single piece of equipment obtrudes itself into one's awareness, each coexists with others in a state of shared latency, waiting, one might say, not passively like a mirror, but with a tendency or disposition to prefigure patterns of behavior, which is how architecture confers orientation." 8

"Like that of its antecedent, the blind's flexibility allowed it to serve as a register and receptacle of the landscape, welcoming it when it presented itself gently, excluding it when it raged with fury." 9

\begin{abstract}
"We begin to see that this corporeal schema is enmeshed within an expanding range of distances, a structured topography that includes where I am, which is to say where the things I now need are within reach, a middle distance, and an expansion towards the clear blue horizon; an equipmental, practical and environmental horizon. Not one of these can be separated from the others, hence the lateral spread of the ensemble that integrates these "rings" into one field, terrain or topography the dining room, the street, and the town or landscape - differentiated but reciprocating." 10
\end{abstract}

For Leatherbarrow furnishings are both register of the body and landscape and a critical mediator of their "lateral spread." Both Leatherbarrow and Leplastrier would seem to suggest that the environmental philosopher Arnold Berleant's strong distinction between participatory and neutrally distanced, picturesque aesthetics is inadequate, that simultaneity or constant rhythmic succession of acts of involvement in and contemplative comportment toward the world characterize aesthetically oriented human experience. But we may also raise the question of the extent to which the reining peacefulness intimated by Leatherbarrow throughout his work, the equipoise of living experience amidst "equipment," has been arrived at after the dust has settled, with primary emphasis on experiential effect (that anticipates subsequent patterns of effects) as opposed to what is affected. Here we find usefulness and accountability in Leplastrier's to furnish, communicating as it does what constitutes architecture and the manner in which it is to be constituted.

With respect to dwelling practices, Leatherbarrow's descriptions of inhabitational behavior seem largely passive and as if our patterns are predetermined rather than in constant adjustment. If rhythms of flux and stasis characterize human existence, an intrinsic propensity to cycle through times of movement and activity and times of rest, what kind of arrangements of furnishings would support such living patterns? Dewey's birdlike metaphor of human affairs as an "alternation of flights and perchings" provides a direction for exploration, as does Glenn Murcutt's notion of architecture as "encampment," suggesting a migratory patterning to human affairs, with residency as temporal and only one form of activity among others that also include gathering, commuting, encountering, bargaining, recreating, wandering, etc. ${ }^{11}$ Dewey and Murcutt's metaphors may offer a more complete - and lightened - accounting of the full range of our being amidst the lateral spread, even beginning to blur distinctions between the domestic and wild, an idea to be taken up shortly.

Lastly, and despite the promise of Leatherbarrow's ideas, "clear blue horizon" as a summary portrayal of our environment seems an overly simple evocation of the enormous and legible complexity that the world as we experience it. Leplastrier's "room" is more ample (with the clear blue horizon as wainscoting?) and hardly nondescript if we consider Heidegger's thoughts on room as interpreted by the contemporary philosopher Edward Casey:

"Heidegger's contribution to this history (of place) is to make room such a mediatrix expressly by virtue of the ingrediency of region, whose amplitude and dynamism make possible the generation

(c) 2007 ARCC Spring Research Conference, Eugene, Oregon, April 16-18, 2007 
of place and space alike. For the effect of region is the creation of the very spatiality (raeumlichkiet: literally, "roomliness") from which place is precipitated and space discerned." ${ }^{12}$

As Casey interprets Heidegger, "room" is enriched in its inclusivity and powers of precipitation, providing full potency to Leplastrier's notion. As we consider how such understandings may play out in the realm of design, one wonders, however, whether room is too generous a term, and that it might be more helpful for architects to develop metaphorical characterizations that more specifically relate qualities of projects to particularities of context. This is a primary reason why engagement with ideas in landscape ecology may prove helpful.

\subsection{THE FOLIAGE OF ARCHITECTURE}

"The animal world and that of plant life are not utilized merely because they are there, but because they suggest a mode of thought." -Claude Levi-Strauss ${ }^{13}$

"Now an increasingly urban population fears any intimacy with uncontrolled nature, especially darkness." -John Stilgoe ${ }^{14}$

Students in the winter 2006 "Triumph of the Commons" architectural design studio were asked to consider increased urban density and improved ecological performance as one interrelated problem. The studio specifically explored simultaneous residential alley-access infill development and oak habitat restoration on a city block in a post war neighborhood in Eugene, Oregon, with a goal to provide for a growing human population resourcefully while reestablishing critical wildlife corridors linking core habitats for threatened species. A landscape ecologist with extensive experience in oak habitat restoration partnered with the author from day one, helping students develop proposals for secondary dwelling units on existing lots and block scale native vegetative structures - superimposed threads of woodland and savanna.
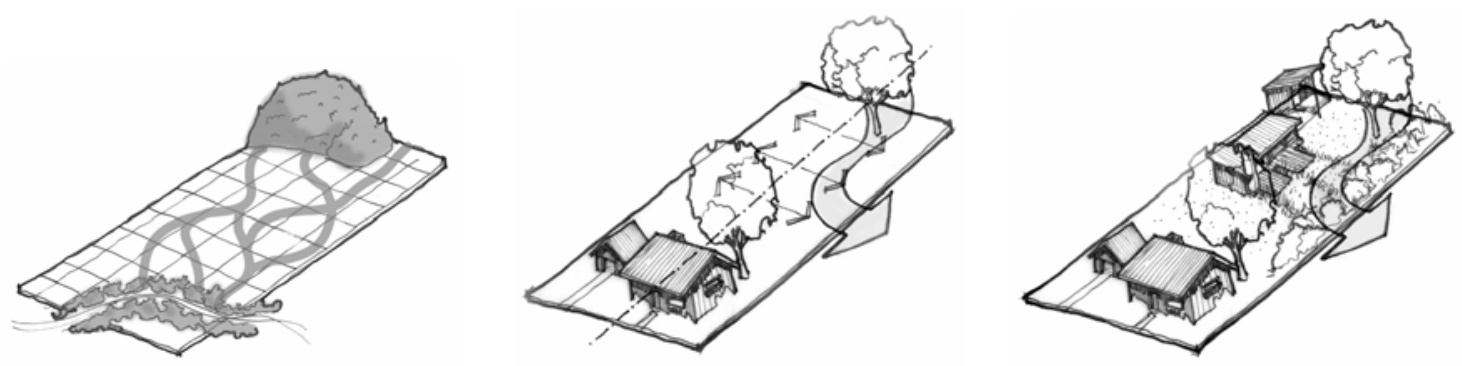

Figures 2, 3 \& 4: (left): Neighborhood goal to (re)create wildlife corridors so as to connect "core" habitats; (middle, right): Siting and configuration of new infill dwelling unit on existing lot in response to neighborhood scale ecological goal of corridor connectivity (drawings by Alex Wyndham, Master of Archiecture candidate)

Initial and exploratory assignments had students generate imagery and associated metaphorical descriptors capturing their insights from readings and discussions on the work of landscape ecologists and observations during field trips to both Eugene's alleys and nearby oak woodland communities. These served as the basis of three-dimensional "form analog" studies that hybridized oak and alley realms into one composite design language that influenced directly more 'pragmatic' design undertakings later in the quarter. Through these investigations, students considered both the architectural implications of the incorporation of landscape ecology principles as they pertain to specific habitat conditions, and the viability of ecological structures such as cores and corridors in a dense urban context. Investigations in section revealed the potential for multiple species to occupy different strata within one vertical band of space, with oaks growing alongside, up and over dwellings, providing summer shade for people below and corridor networks of limbs facilitating movement for the western grey squirrel and other creatures above. 

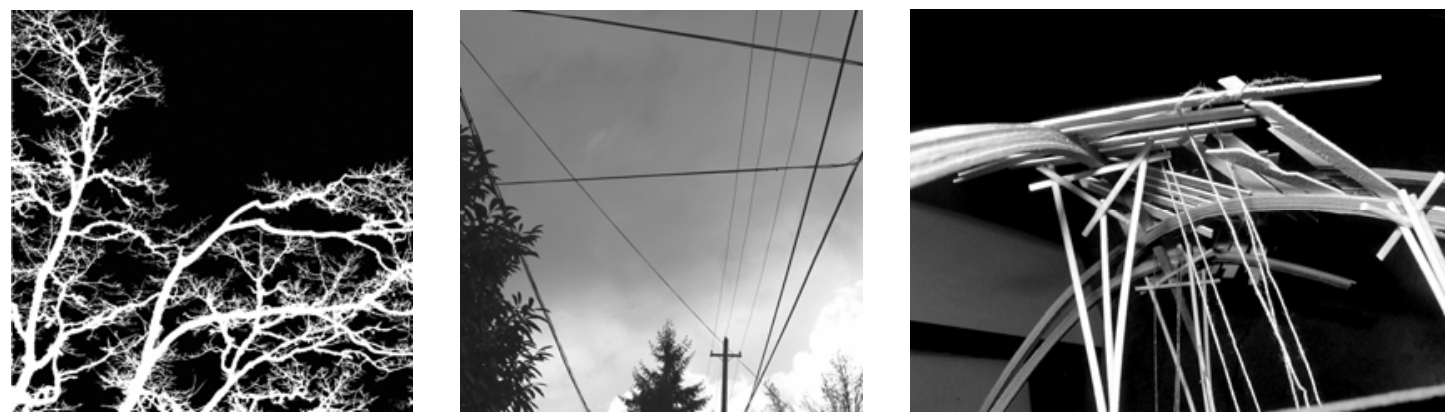

Figures 5, 6 \& 7: Brent Sturlaugson's oak pattern image," Rebekah Matheny's alleyway power lines image, and Missa Aloisi's "Lifelines" hybrid oak/alley "form analog" study

Gilles Deleuze and Felix Guattari, in their poststructuralist masterpiece $A$ Thousand Plateaus, favor the "rhizomatic" over the "arborescent" model in describing societies and relationships, directing our understanding of arborescence towards the trunk, a metaphorical pillar of centralized command. In so doing they overlook the bud and the branch, the latter not predetermined in its course of growth and yet reacting to its neighbors in seeking light and continued livelihood. Extending our gaze upward, from understory and trunk to the tracery of interwoven limbs, we are afforded a pluralistic, democratic impression, inspiring possibilities for open, interconnected and "branching" spatial organizations of built and open space. With Brent Sturlaugson's scheme for example, a contiguous canopy overhead corresponds to a contiguous social understory, ribbons of outdoor space emanating from a ribbon-like toplight serving as his dwelling's primary organizational element. Missa Aloisi's inspirational insight was that of a bird descending from its home on an oak limb to pluck berries from a shrub below, experiencing a brief moment of exposure in flight. Her dwelling separates eating and living space from sleeping "pods" (reminiscent of oak galls), with the human inhabitant's periods of shelter in these book-ended realms offset by brief, vulnerable movements within translucent "lifeline" passages.

That oaks undergo seasonal changes - budding, leafing, shedding - and that these cycles generate dramatically different thermal and luminous microenvironments, had perhaps the greatest impact on perceptions of space making, inspiring dynamic architectures capable of expansion and contraction. With Alex Wyndham's "Deciduous House," insulated wall "leaves" fold upward and serve as south facing trellis-like shade screens in summer, filtering light from above. With several studio projects, the dwelling expands in summer as wall panels slide laterally into recessed niches, maximizing horizontal continuity between interior and exterior space. An 800 square foot dwelling unit suddenly feels spacious when open to a reinvigorated network of natural systems, where viewsheds extend to adjacent lots and beyond, thoughtfully and so as to not create conflicts of privacy.

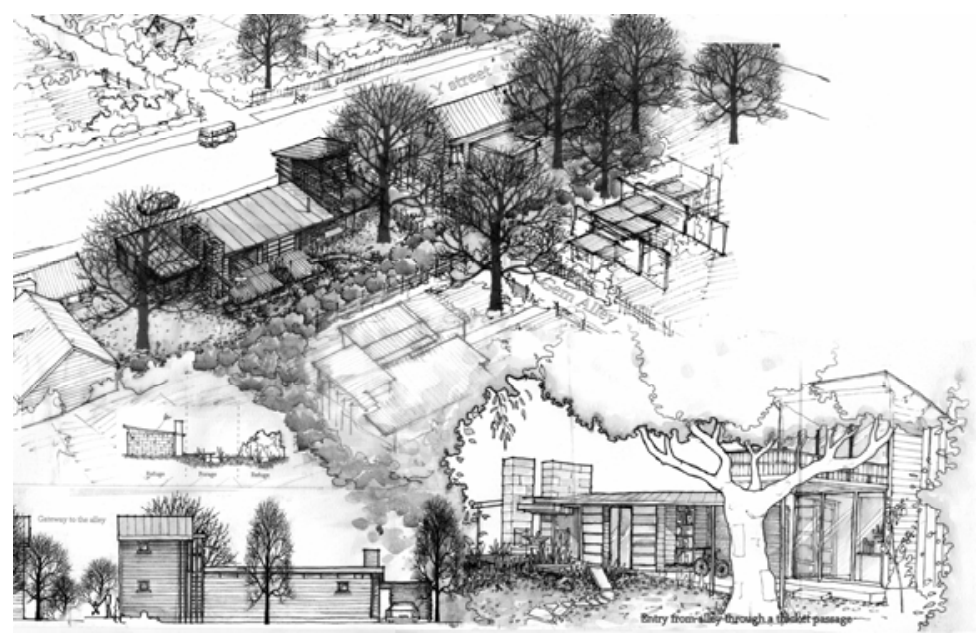

Figure 8: Alex Wyndham's final project "Deciduous House" 
In winter mode, architectural elements contract and dwellings become snugly introspective, surrounded by silent matt grey light, gentle rain and black wet limbs of the Pacific Northwest. January dimness counterbalances the light exuberance of summer; our world becomes closer and more immediate, paralleling the inwardness of our own comportment. With Tanizaki, we recognize darkness not as blackness but consisting of countless gradients, from tangible opacity to endless depth. ${ }^{15}$ With Derrida, we harbor suspicion of a society's insistence on unceasing immersion in light:

"The heliological metaphor turns away our glance. For it has always been believed that metaphors exculpate, lift the weight of things and of acts. If there is no history, except through language, and if language is elementally metaphorical, Borges is correct, 'Perhaps universal history is but the history of several metaphors.' Light is only one example of 'several' fundamental 'metaphors,' but what an example! Who will ever dominate it, who will ever pronounce it's meaning without first being pronounced by it?" 16

\title{
3.0 A PALETTE OF HUMAN ACT/ENVIRONMENT "CASE" METAPHORS
}

\author{
"The ephemerality of all our acts puts us into a kind of wilderness-in-time"-Gary Snyder ${ }^{17}$ \\ "If the objects of the environment were only as plastic as the materials of poetic art, men would \\ never have been obliged to have recourse to creation in the medium of words." -John Dewey ${ }^{18}$
}

The efforts and ruminations described above have coalesced in the development of a palette of "case study" metaphors for use in the design studio. Building from Leplastrier's compound notion and the "Triumph of the Commons" pilot studio experiment, and borrowing more explicitly from the language of landscape ecology, these metaphors, it is hoped, will catalyze possibilities for sensitive acknowledgment of context as a consequence of architectural intervention. A winter 2007 "Wild Urbanism" studio provides the first opportunity to introduce these to advanced design students. The project, a vertical mixed-use development adjacent to a riparian/mixed hardwood-conifer forest in Portland, OR, anticipates the brief for a fall 2007 Portland Metro Services "Nature in Neighborhoods" competition of which the author is serving as consultant. Students will develop 2D and 3D "esquisse" studies at several strategic points in the quarter that will require relating a case metaphor to the building program and site, with the expectation that both built and natural features are represented (that we contend with human and non-human habitation throughout). A goal will be to examine whether the metaphors influence the generation of design proposals that contend with human needs and aspirations and the ecological integrity and viability of critical and singular habitats.

The case metaphors include:

- flights and perchings along a green frame

- peninsular interdigitation

- folds along waterpockets

- embroidered pleats in green wedges

- encampments in a green fabric
- $\quad$ dispersing corridors

- layers buffering cores

- stitching matrices and cores

- watermarks

- boulder garden and a braided stream

Several of these case metaphors stem directly from operative concepts in landscape ecology. "Dispersing corridors" for example derives from the notion of a "dispersal corridor," typically a band of native vegetation facilitating migration of wildlife from one "core" habitat area to another. Others combine philosophical and landscape ecological notions, as with "alternations of flights and perchings along a green frame" that links Dewey's aforementioned birdlike articulation of human activity with a concept of a "network of green space for an urban area." ${ }^{19}$ Similarly, "embroidered pleats in green wedges" compounds Gilles Delueze' cloth-like metaphor as the archetype of Baroque sensibility with an ecological concept for a landscape structure that "keeps developed areas apart while bringing greenspace closer to heart of settlement." 20 All case metaphors are intended to capture an understanding that return to ecological health in urban environments involves design, artfulness, intention and beauty. These inventive (re)characterizations attempt to reconcile ever-growing human presence with need for the wild in places largely compromised yet capable of rejuvenation.

(c) 2007 ARCC Spring Research Conference, Eugene, Oregon, April 16-18, 2007 
In the aftermath of this studio experiment I will evaluate the impact of the case metaphors on the environmental performance and ecological impact of students' projects. This will entail (1) examination of the case metaphors that students utilized; (2) an appraisal of how students organized the building program for the project under consideration and an estimate of the effect of case metaphors on organization; (3) a determination of the percentage of spaces in students' projects that are fully, partially and unconditioned; (4) an estimation of energy savings of proposed designs over more traditionally organized buildings using the same program and where spaces are assumed fully conditioned. I also intend to assess the ecological impact of student projects through consideration of: extent of building footprint, where a small footprint would have less ecological impact that a large footprint; and degree of "permeability" of the site as a result of building configuration, with a goal to facilitate wildlife movement through the site to adjacent habitat areas and where wider, uninterrupted and more wildlife corridors are preferred over narrower, interrupted and fewer wildlife corridors.

\subsection{TRAJECTORIES}

"Ecosystem deterioration...needs to be addressed by a series of bold experiments to test the success of integrated management" -Jeremy Jackson et. al. ${ }^{21}$

"Since man was constituted at a time when language was doomed to dispersion, will he not be dispersed when language regains its unity?" -Michael Foucault ${ }^{22}$

The philosopher Edward Casey maintains, "By 'strung out between wilderness and site,' I mean that we drastically lack viable and significant intermediate positions between these two extremities." 23 Fellow philosopher Hans-Georg Gadamer suggests "discourse that is intended to reveal something requires that the thing be broken open by the question." ${ }^{24}$ Questions originating in the field of landscape ecology break the resolute "thingness' of architecture in compelling ways, and our responses as designers open stimulating paths of inquiry for our newfound collaborators. Together we can more effectively find those intermediate positions that Casey believes contemporary culture so desperately needs, discovering new life for our disciplines in the process.

Yet in our efforts to envision and describe more symbiotic relationships between built and natural environments, humans and other organisms, are we are compelled to speak in reductivist binaries, thereby confronting the limits of a language that necessarily presupposes the nature/culture duality we seek to circumvent? Perhaps not if we consider the connections between architectural and ecological systems as manifold, and our charge as not the portrayal of parallels but the rendering of entanglements through associative, metaphorical thinking. Encouraged by Richard Rorty to "replace the world of pictures constructed with the aid of Greek oppositions with a picture of a flux of continually changing relations," we may affect a redistribution of categories, a traversal and interdigitization of nature/culture binaries that increases the frequency of their oscillation. ${ }^{25}$

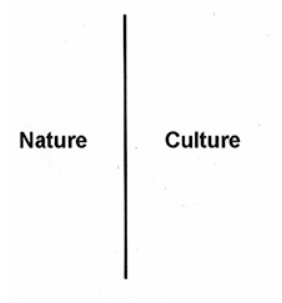

polarization

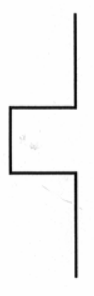

overlap

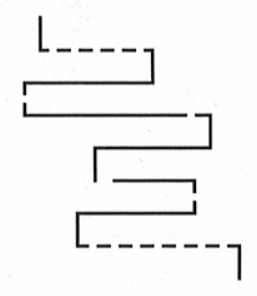

interdigitation

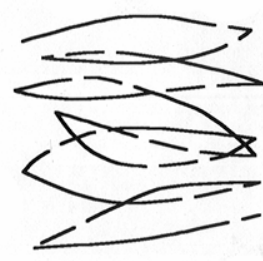

oscillation

Figure 9: Evolving relationships of nature/culture and ecology/architecture (and our descriptions thereof)

For students in the studios described above, it is hoped that playful, tenacious engagement of metaphor and the language of landscape ecology generates an outward reverberation of thought, inspiring notions of ecological symbioses between buildings and sites, dramatic material and energy efficiencies, and profound engagement of humans and the natural world. Through exposure to human 
act/environment metaphors, it is hoped, students are alerted to the inherent incompleteness of architectural undertakings, of the advantages of "a project that privileges unpredictable ecological processes," and of the benefits of invitation of the wild in the design of urban environments. ${ }^{26}$ Awareness that the identities of specific ecological structures can help us conceptualize our own relationships and artifacts opens us to radical possibilities for migratory proto-urbanism and community revitalization, to depictions of cross flows not yet appreciated, architectural ecologies both selectively porous and biologically complex.

\section{REFERENCES}

${ }_{1}^{1}$ From Richard T.T. Forman \& Michel Godron, Landscape Ecology, New York: John Wiley \& Sons, 1986

${ }^{2}$ Monica G. Turner, Robert H. Gardner and Robert V. O'Neil, Landscape Ecology in Theory and Practice: Patterns and Process, New York: Springer Science and Business Media, Inc., 2001, p. 1

${ }^{3}$ Joan Iverson Nassuaer, "Cultural Sustainability: Aligning Aesthetics and Ecology" in Placing Nature: Culture and Landscape Ecology, Joan Iverson Nassuaer, ed. (Washington, D.C.: Island Press, 1997), p. 71

${ }^{4}$ James D. Proctor and Brendon M. H. Larson, "Ecology, Complexity, and Metaphor," in Bioscience Volume 55, No.12, December, 2005, p. 1066

${ }^{5}$ For a thorough consideration of Leplastrier's articulation, please see my papers "Metaphor, Architectural Design and Environmental Response," Architectural Research Centers Consortium/European Association of Architectural Education International Conference, Philadelphia, PA, 2006 and "Lightness of Building: Furnishing a Regenerative Architecture," American Collegiate Schools of Architecture Annual Conference, Louisville, KY, 2003

${ }^{6}$ Gary Snyder, "Blue Mountains Constantly Walking," in The Practice of the Wild, Washington, D.C.: Shoemaker and Hoard, 1990, p. 112

${ }^{7}$ My understanding of metaphor has been influenced greatly by George Lakoff and Mark Johnson, in particular their pioneering works Metaphors We Live By and Philosophy in the Flesh

${ }^{8}$ David Leatherbarrow, Uncommon Ground: Architecture, Technology, Topography, Cambridge: MIT Press, 2000, p. 157

${ }^{9}$ David Leatherbarrow, p. 138

${ }^{10}$ David Leatherbarrow, p. 66

${ }^{11}$ John Dewey, Human Nature and Conduct, Mineola, NY: Dover Publications, Inc., 2002 (originally published by Henry Holt \& Company, New York, 1922), p. 179

${ }^{12}$ Edward S. Casey, The Fate of Place: A Philosophical History, Berkeley, CA: University of California Press, 1997, p. 252

${ }^{13}$ Claude Levi-Strauss, Totemism, Rodney Needham, trans., Boston: Beacon Press, 1962, p. 13

${ }^{14}$ John Stilgoe, "Land Fear: Wildness and the Bewilderment of the City Dweller," in Architecture Boston, March/April 2003, pp. 20

${ }^{15}$ See Jun'ichiro Tanizaki, In Praise of Shadows, Thomas J. Harper and Edward G. Seidensticker, trans, New Haven, CT: Leete's Island Books, 1977

${ }^{16}$ Jacques Derrida, "Violence and Metaphysics," in Writing and Difference, Alan Bass, trans., Chicago: University of Chicago Press, 1978, p. 92

${ }^{17}$ Gary Snyder, "On the Path, Off the Trail," in The Practice of the Wild, Washington, D.C.: Shoemaker and Hoard, 1990, p. 165

${ }^{18}$ John Dewey, pp. 256-257

19 Paul Caewood Hellmund and Daniel Somers Smith, Designing Greenways: Sustainable Landscapes for Nature and People, Washington, D.C.: Island Press, 2005, pp. 2-3

20 See Gilles Deleuze's The Fold: Leibniz and the Baroque, Tom Conley, trans., Minneapolis: University of Minnesota Press, 1993 and Paul Caewoood Hellmund and Daniel Somers Smith, pp. 2-3

${ }^{21}$ Jeremy B.B. Jackson, et. al., "Historical Overfishing and the Recent Collapse of Coastal Ecosystems," Science, Volume 293 No. 5530, July 27, 2001, pp. 629-638

${ }^{22}$ Michael Foucault, The Order of Things: An Archaeology of the Human Sciences, New York: Vintage Books, 1994 edition, p. 386

${ }^{23}$ Edward S. Casey, Getting Back Into Place: Toward a New Understanding of the Place World, Bloomington, IN: University of Indiana Press, 1993, p. 259

${ }^{24}$ Hans-Georg Gadamer, Truth and Method, Joel Weinsheimer and Donald G. Marshall, transl., London: Continuum Publishing Group, 2004 edition, p. 357

${ }^{25}$ Richard Rorty, "A World Without Substances or Essences," in Philosophy of Social Hope, New York: Penguin Books, 1999, p. 46

${ }^{26}$ Eric Higgs, Nature By Design: People, Natural Process and Ecological Restoration, Cambridge, MA: MIT Press, 2003, p. 7 